\title{
AS ESPARSAS NO CANCIONEIRO GERAL DE GARCIA DE RESENDE: FORMA E CONTEÚDO
}

\section{THE ESPARSAS IN GARCIA DE RESENDE'S CANCIONEIRO GERAL: FORM AND CONTENT}

\author{
Geraldo Augusto Fernandes ${ }^{1}$ \\ Universidade Nove de Julho
}

Resumo: As esparsas são uma das formas poéticas de que se valeram os poetas palacianos portugueses presentes no Cancioneiro Geral de Garcia de Resende, editado em 1516. Sua característica é ser monostrófica, servir ao improviso e ao desenvolvimento de máximas, exempla, ditos, caros ao homem medieval. De forma fixa, as esparsas propiciaram possibilidades variadas de gênero e de conteúdo, aliando tradição e inovação. No Cancioneiro de Resende, distinguem-se quatro espécies de conteúdos temáticos.

Palavras-chave: forma e conteúdo; tradição e inovação; improvisação
Abstract: The esparsas are one of the poetic forms developed by the Portuguese courtly poets present in the Cancioneiro Geral, edited by Garcia de Resende in 1516. The esparsa is a poem with only one strophe, and is fit for improvisation and for the development of maxims, exempla, dictum, which were highly esteemed by the man of Middle Ages. Fix in its form, the esparsas provided many possibilities in gender and content, allying tradition and innovation. In Resende's songbook four species of thematic contents can be found.

Keywords: form and content; tradition and innovation; improvisation

\footnotetext{
${ }^{1}$ Doutor em Literatura Portuguesa, Universidade de São Paulo. E-mail: geraldoaugust@uol.com.br.
} 
As esparsas pertencem a um dos seis grupos de formas poéticas presentes no Cancioneiro Geral de Garcia de Resende, compilação de 880 poemas escritos entre 1449 e 1516, ano da publicação do compêndio. São 81 composições, o que corresponde a $9,2 \%$ do total de peças do Cancioneiro. A esparsa caracteriza-se por ser monostrófica, cuja extensão varia de oito a 16 versos e é própria para o improviso". Pierre Le Gentil comenta que "les esparsas sont donc des impromptus, comme on les aime à toutes les époques de préciosité [e que] les esparsas se font particulièrement fréquents dans les recueils de caractère mondain ${ }^{3 "}$. Le Gentil inclui as esparsas, bem como as letras ${ }^{4}$ e as ajudas ${ }^{5}$ em "genres mineurs", e diz que os poetas peninsulares não somente tomaram as esparsas às coblas esparsas das Leys d'Amors, mas, principalmente, "ils ont encore imaginé des types nouveaux. On pourrait alors se demander s'ils ont eu connaissance du strambotto italien, et s'en sont aussi inspirés..." ${ }^{\prime \prime}$. Segundo Massaud Moisés, a origem das esparsas está nos madrigais e epigramas e nelas "se condensa um pensamento artisticamente empregado ${ }^{7 "}$. A definição do estudioso retrata um fato real quanto ao pensamento artisticamente trabalhado,

\footnotetext{
${ }^{2}$ António J. Saraiva e Óscar Lopes dizem que a esparsa é um gênero livre, "de uma estrofe só, que varia entre oito, nove e dez versos". (SARAIVA, A. J. \& LOPES, Ó. História da Literatura Portuguesa. 16 ed. Porto: Porto Ed., [s.d.], p. 161). António Corrêa de Oliveira e Luis Saavedra Machado definem a esparsa "do 1. sparsa, p.p. de spargere, semear, espalhar, dispersar [por] uma composição de uma só copla, que pode ter 8,9 ou 10 versos, raras vezes mais. O assunto é geralmente triste". (TEXTOS Portugueses Medievais. (Org.) Luis Saavedra Machado \& António de Corrêa Oliveira. Coimbra. Atlântida Ed., 1959, p. 202). No entanto, a ocorrência de esparsas longas vai muito além das "raras vezes", e o assunto "triste" pode equiparar-se a assuntos mundanos, amorosos e filosóficos. Joaquín González Cuenca, editor do Cancionero General de Hernando del Castillo, de 2003, comenta que "la esparsa o esparza [Castillo prefiere siempre esparsa] es una composición lírica que consta de una sola estrofa. Abunda en el Cancionero general..." (CANCIONERO General de Hernando del Castillo. Ed. Joaquín González Cuenca. Madri: Ed. Castalia, 2004, p. 284, Tomo I).

${ }^{3}$ LE GENTIL, Pierre. La poésie lyrique espagnole et portugaise à la fin du Moyen âge: les thèmes, les genres et les formes. 2 vol. Rennes: Plihon, 1949, p. 218-219.

4 "Moto ou mote, palavras breves de que se usa nas medalhas, moedas, divisas, empresas, encerrando um pensamento, um ideal de vida, a afirmação de um sentimento." (DIAS, Aida Fernanda. Cancioneiro Geral de Garcia de Resende - Dicionário (Comum, Onomástico e Toponímico). Maia: Imprensa Nacional - Casa da Moeda, 2003. Volume VI, p. 398).

${ }^{5}$ Subgênero característico do Cancioneiro Geral, em que um poeta, ou poetas, é instigado a ajudar o proponente e, quase sempre, é este quem pede. Pierre Le Gentil comenta que "les ajudas rappelent, aussi bien par leur forme que par leur contenu, les esparsas, les unes et les autres remontant, semble-t-il, aux coblas esparsas des Provençaux. Il est curieux de voir ainsi renaître et se développer, en plein XVe. siècle, un genre qui paraissait oublié..." (LE GENTIL, op.cit., p. 221).

${ }^{6}$ Idem, p. 221-222.

${ }^{7}$ DICIONÁRIO de termos literários. Massaud Moisés. São Paulo: Cultrix, 2004, p. 165.
} 
pois, como se verá, mesmo a partir de um fato trivial, muitas esparsas podem ser consideradas adágios, ditos, exemplos ${ }^{8}$.

Na Compilação de Garcia de Resende, no entanto, há alguns poemas cuja extensão é variada e que, por motivos de classificação, serão considerados "esparsas com defeito", como as de números 331 e 344, monostróficas, compostas de cinco e seis versos, respectivamente. Eis os dois poemas, à guisa de exemplificação:

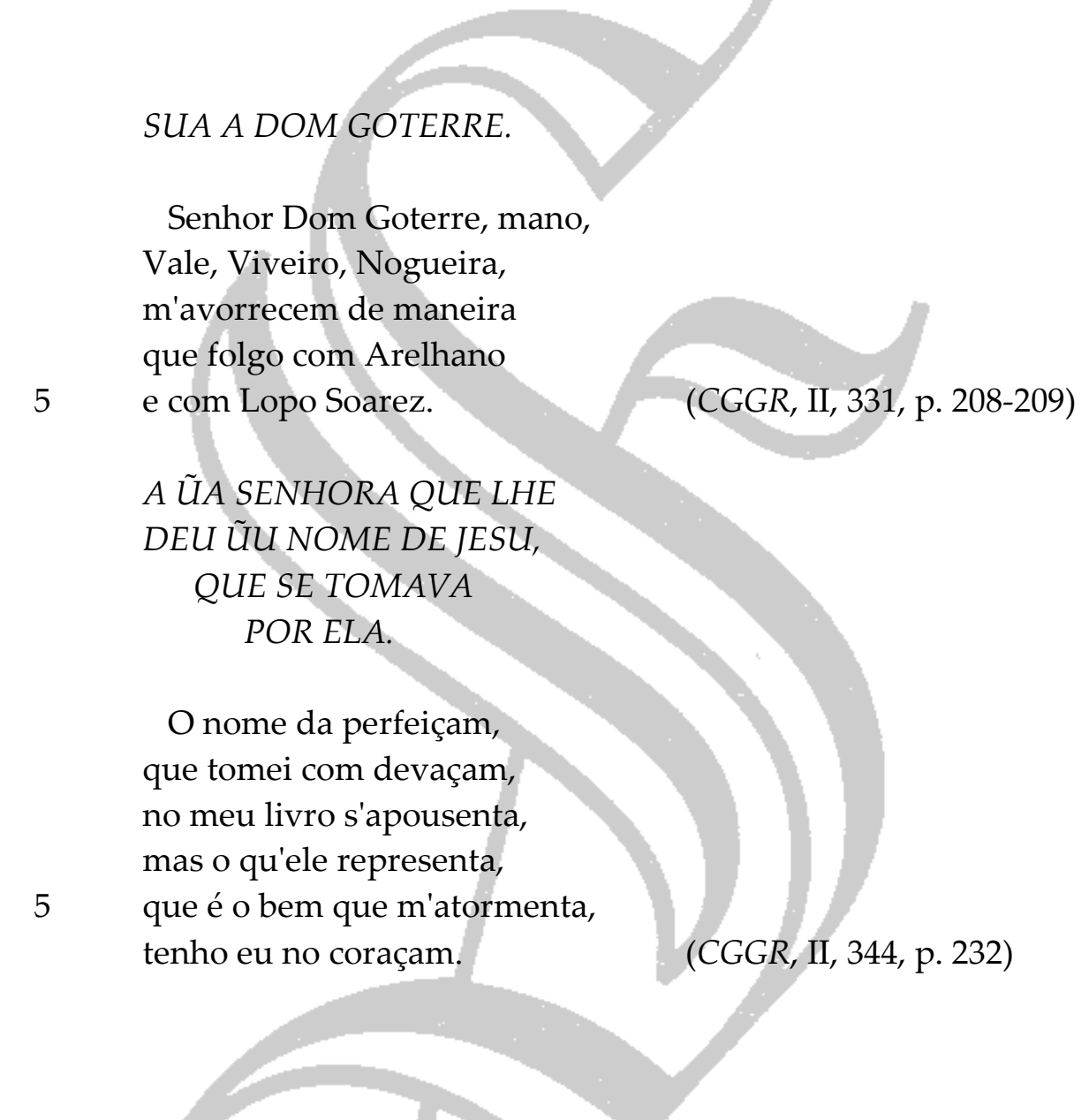

Trata-se, o primeiro poema, de uma esparsa circunstancial e nada mais é do que um desabafo do poeta João Fogaça com relação a três personagens palacianas que lhe desagradavam. Por outro lado, demonstra apreço por outros

\footnotetext{
${ }^{8}$ Quanto a esse recurso, o exemplum, tão do gosto medieval, Maria Isabel Morán Cabanas comenta: "Quando o trovador ou o poeta deseja mostrar a maneira em que se manifesta uma determinada situação amiúde lança mão deste tipo de recurso, já que os exempla apoiam-se sobre a base de um ser ou de um facto famoso e, portanto, conhecido por todos, fazendo com que a comparação resulte mais simples e fácil de compreender para o ouvinte ou leitor de seus versos". (MORÁN CABANAS, Maria Isabel. O exemplum na lírica amorosa medieval GalegoPortuguesa e do Cancioneiro Geral. In: Retórica, Política e Ideología desde la Antegüedad hasta nuestros días. Retórica Clásica y Edad Média. (Actas del II Congreso Internacional). Salamanca, Logo, 1997, vol. I, p. 355).
} 
dois: Juan Ramírez Arellano, castelhano, Senhor dos Cameros, que esteve a serviço da corte portuguesa em 1453. O outro personagem é, provavelmente, o capitão enviado à Mina por D. João II, e que gozou de grande consideração entre seus conterrâneos ${ }^{9}$. Quanto ao segundo poema, de Diogo Brandão, a didascália mostra-se ambígua pelo uso do pronome "lhe" - a quem se refere? Ao poeta ou à senhora? Se se referir a ela, trata-se, é claro, de sátira; se a referência for ao poeta, mostra ele desconforto por ser comparado a Cristo. Mesmo assim, o verso "bem que me atormenta" deixa vaga a ideia desse tormento, se relacionado a Jesus. Trata-se, ambas as esparsas, de pura circunstancialidade $\mathrm{e}$, sem as referências, torna-se dificultosa qualquer interpretação. No entanto, mostram musicalidade e poeticidade, devido à métrica, à rima e ao ritmo.

Ainda quanto à esparsa, enquanto monóstrofe, é preciso levar-se em consideração algumas trovas, cuja característica é assemelharem-se à estrutura da esparsa. Tomem-se como exemplo as trovas que aparecem no poema no. 1, "O cuidar e sospirar", que abre o CGGR ${ }^{10}$. Apesar de feito para leitura única, em que há várias formas em um só poema, com temática também única, muitas trovas ali podem ser consideradas "esparsas" se tomadas isoladamente, como se fossem um exemplum, um ditado ou mesmo um poema completo. Veja-se a trova em que Nuno Pereira se dirige a Jorge da Silveira, comentando o sofrimento que a senhora a quem serve lhe provoca no coração. Na verdade, como se pode observar, o coração é que aparece como interlocutor do poeta. Pela forma, uma décima, e pelo conteúdo, o poema poderia ser classificado como "esparsa", se fosse lido isoladamente:

SUA A JORGE DA SILVEIRA.

Diz-m'a mim meu coraçam, porque m'a isto nam calo:

- Pera que vos dou rezão, pois vos nam chega paixam

5 deste cuidado que falo?

Ca se vos ele apertasse

\footnotetext{
9 Ambas as referências a estes personagens encontram-se em DIAS, op.cit., 2003, pp. 482; 655; 710; 733 e 748.

${ }^{10}$ A abreviatura CGGR será usada para indicar o Cancioneiro Geral de Garcia de Resende. A edição utilizada é a mais recente, de 1990-1993, empreendida por Aida Fernanda Dias, que fixou o texto, estudou-o (no Volume V, "A Temática", de 1998) e organizou um Dicionário Comum, Onomástico e Toponímico (Volume VI), de 2003. A publicação é da Imprensa Nacional-Casa da Moeda, Maia. Dessa forma, todas as referências a número dos poemas, volume e às páginas em que estes se encontram remetem à edição da estudiosa.
}

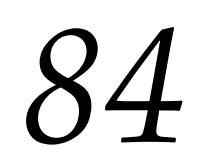




\title{
Revista Signum, 2011, vol. 12, n. 1.
}

\author{
assi como m'ele aperta, \\ e o vosso assi penasse, \\ dirieis que se julgasse

Outro exemplo relevante é a participação de Gil Vicente em um poema de formas mistas"1, também um "processo", em que vários contendores, uns em defesa, outros contra, debatem se a causa de Vasco Abul, o reclamante, é justa ou não. Abul teria presenteado com uma "cadea d'ouro", que ele mesmo trazia ao pescoço ${ }^{12}$, uma moça que bailava em Alenquer, e depois queria de volta o presente dado. O processo, assim como "O cuidar e sospirar", apresenta elementos de teatralidade ${ }^{13} \mathrm{e}$, nesta trova de Mestre Gil, pode-se perceber certa independência do texto, podendo ser considerado um exemplum, somado à gradação e ao adynaton:

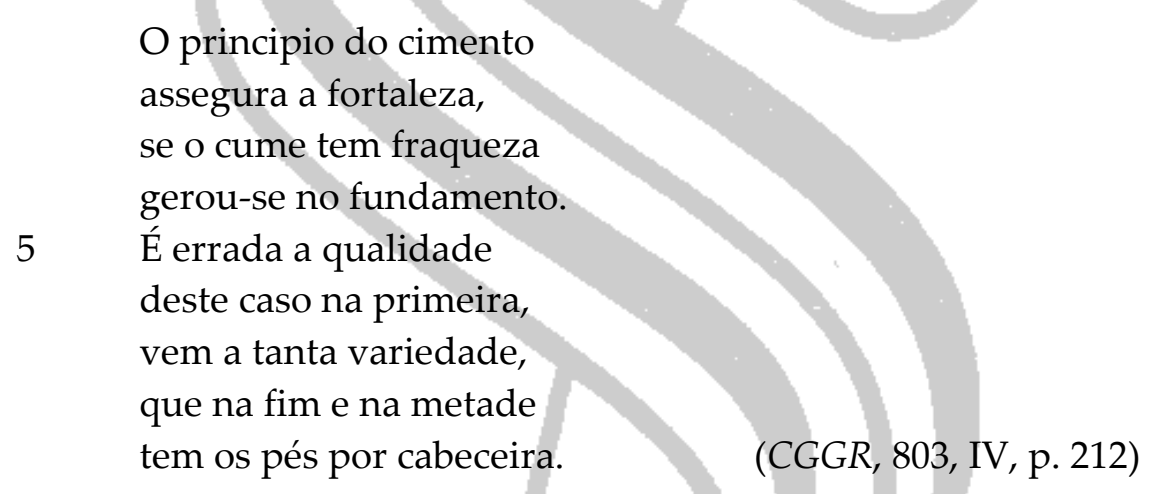

Tanto as esparsas quanto as trovas desenvolvidas pelos poetas palacianos diferenciam-se das baladas, dos vilancetes e das cantigas basicamente por não apresentarem estrofes como "fim" em número reduzido de versos, caso das

${ }^{11}$ A característica original desse tipo de composição poética é a mescla de várias formas numa só composição. Tome-se como exemplo o texto que abre o CGGR, conhecido por "O cuidar e sospirar". Trata-se de 146 poemas numa só composição, desenvolvendo um único tema: 116 trovas, uma sextilha, cinco quadras, uma quintilha, 22 cantigas e um vilancete. Além desse poema, selecionei outros 95, cuja forma é mista e serão tema de estudo no capítulo II.

12 Parece ser moda da época o uso dessas "cadeas d'ouro", provavelmente resultado do comércio marítimo: na trova no. 57, Álvaro de Brito Pestana diz: “... com ricos trajos finos, / cadeas d'ouro, colares, / engrandecem" (CANCIONEIRO Geral de Garcia de Resende. Fixação do texto e estudo por Aida Fernanda Dias. Maia: Imprensa Nacional-Casa da Moeda, 1998. Volume I, p. 218); também na cantiga no. 364 de Duarte de Lemos aparece tal referência: "Senhor, vossa mercê crea / que despachei mal o moço, / por nam tirar a cadea / do pescoço. (Idem, II, p. 255).

${ }^{13}$ Estudo dessa peça em MORÁN CABANAS, Maria Isabel. Festa, teatralidade e escrita. Esboços teatrais no Cancioneiro Geral de Garcia de Resende. A Coruña: Biblioteca-Arquivo Teatral Francisco Pillado Mayor, 2003. 


\section{Revista Signum, 2011, vol. 12, n. 1.}

baladas, ou como "mote", caso dos vilancetes e cantigas; como é composta de apenas uma estrofe, a esparsa, diferente da maioria das trovas, dispensa o "fim". A esparsa nunca ultrapassou, em Portugal, os 13 versos, diferentemente de seu congênere francês, e, como todas as outras composições compiladas no CGGR, varia seu conteúdo temático, servindo quer para o nobre sentimento do amor, quer para a expressão da sátira.

As esparsas do compêndio de Garcia de Resende estão espalhadas pelos quatro volumes do Cancioneiro. Percebe-se que o maior número delas se encontra no último volume e apresentam certa tendência ao refinamento. A maioria dos poemas deste volume foi escrita na proximidade do fim do Quatrocentos e no início do Quinhentos - atentando-se ao fato de que o CGGR, como dizem vários estudiosos, prenuncia o Renascimento português. Pode-se afirmar com segurança que o refinamento alegado tem a ver com esse prenúncio. Observe-se, ainda, que as trocas culturais entre Portugal e Castela, e também com Itália e França, permitiram aos poetas cortesãos tal apuro estilístico e formal. Note-se também que, assim como a cantiga - forma essencialmente medieval -, a esparsa volta a ser cultivada numa época em que os poemas compostos em arte maior despontavam como grande novidade. É possível que isso se explique pelo fato de os poemas de curta extensão serem apropriados ao improviso e à sociabilidade paçã, mas também porque as esparsas trazem em seu bojo, mais especificamente em sua forma, a abertura para expressão de máximas, exemplos, ditos, matérias tão caras ao homem medieval.

Das 81 esparsas, cinco vêm redigidas em castelhano; 22 apresentam pés quebrados $^{14}$ - neste item, destaque-se que apenas uma (no. 526) apresenta um pé quebrado dissilábico e outro tetrassilábico; também nesse grupo, os pés quebrados estão alternados, i.e., aparecem em versos não sequenciais. Assim

${ }^{14}$ Conforme Juan del Encina, "ay outro género de trovar que resulta de los sobredichos (i.e., ‘De lo principal que se requiere para aprender a trovar', capítulo iiij de sua Arte D'Poesía), que se llama pie quebrado, que es medio pie, así de arte real como de mayor; del arte real son cuatro sílabas o su equivalencia, y este suélese trovar el pie quebrado mezclado con los enteros, y a las veces pasan cinco sílabas por medio pie, y entonces dezimos que va la vna perdida, assí como dixo don Jorge [Manrique?]: como debemos. En el arte mayor quando se parten los pies y van quebrados, nunca suelen mezclarse con los enteros, mas antes todos son quebrados, según parece por muchos villancicos que ay de aquesta arte trovados". ENCINA, Juan del. Arte de poesía. In: Las poéticas castellanas de la edad media. Ed. Francisco López Estrada. Madri: Taurus, 1984. p. 88). Para o poeta, então, não há pés quebrados em arte mayor, somente hemistíquios. Não difere da definição de Antonio de Nebrija, apesar de esta ser mais erudita: "así que el verso que los latinos llaman monómetro, y nuestros poetas pie quebrado, regularmente tiene cuatro sílabas, y llámanle así porque tiene dos pies espondeos, y una medida de asiento...". (NEBRIJA, Antonio de. Gramática de la lengua castellana. Disponível: www.antoniodenebrija.org/indice.html. Acesso em: 26.3.08. Livro II, Cap. VII). Em seguida, o gramático apresenta um exemplo dos Provérbios de Jorge Manrique. 
como em muitas referências às outras formas, Garcia de Resende tende, algumas vezes, a confundir "esparsa" por "trova". Essa troca dá-se nos poemas de números 64, 319, 332, 463, 470, 476, 544, 759, 820 e 826. Na esparsa 443, Resende prefere "copra" a "esparsa". Todas as composições deste grupo estão metrificadas pelo redondilho maior.

Quanto a conteúdo, podem-se distinguir quatro espécies:

a) 33 esparsas de circunstância; dessas, três fatos triviais são mote para a criação de um dito; cinco são satíricas; uma faz referência à Antiguidade e uma usa o recurso da metalinguagem, fato um tanto inusitado para poesias medievais;

b) 31 esparsas de amor; registre-se que a temática amorosa em cinco desses poemas decorre de um fato circunstancial, e duas esparsas condensam um exemplum;

c) cinco esparsas relatam um novo tema, muito explorado pelos poetas palacianos: o "eu" dividido;

d) as outras esparsas podem ser assim distribuídas: uma sobre a tristeza; duas referem-se a um tema recorrente nos textos poéticos medievais, a "pena", no sentido de sofrimento; uma constitui-se de uma prece, logo de assunto religioso; uma também trata da religiosidade (uma "devoção", à moda das "devocións" do Cancionero General de Hernando del Castillo); uma é elegíaca: tradução do epitáfio a Tibulo15; duas têm por temática a vida, transparecendo nelas um cunho filosófico; uma recorre a outro tema característico da Idade Média: bem versus mal, e uma outra, a uma preocupação recente: os novos tempos, aqueles de transição, de descoberta de uma nova era.

Com relação aos gêneros, nas esparsas, assim como nas cantigas e nos vilancetes, torna-se difícil identificá-los com precisão, pois parecem confundir-se forma e gênero, uma vez que essas três formas comportam, primordialmente, $\mathrm{o}$ gênero glosa. Aqueles possíveis de se identificar assim se apresentam: onze epístolas, quatro respostas, três conselhos, duas perguntas, duas glosas, duas de louvor, uma de deslouvor, um epigrama, um memorial, um breve, uma ajuda, um acróstico, uma oração, uma epístola com resposta. Nas esparsas, os poetas desenvolvem o gosto pela comunicação - as "lettres missives". Paul Zumthor

15 "Poeta latino, nascido em Roma em 54 a.C. e que morreu cerca do ano 19 da era cristã". (DIAS, op.cit., 2003, p. 685). 
num artigo dedicado exclusivamente à poética dos Grands Rhétoriqueurs franceses, comenta sobre o gênero epistolar e a importância dele no desenvolvimento da poesia do fim de Quatrocentos e início de Quinhentos. Começa por definir os motivos de tais textos, os quais se assemelham aos dos poetas cortesãos do CGGR: "En vertu de la dispersion géographique à la fois, et de la force des liens personnels entre membres du gran jeu de la cour, l'êpitre est l'une des formes de discours les plus profondément enracinées dans la pratique des rhétoriqueurs ${ }^{16 " . ~ E m ~ s e g u i d a, ~ Z u m t h o r ~ d e s c r e v e ~ o s ~ p r e t e x t o s ~ p a r a ~}$ a escritura de cartas poéticas:

Mais, sous le prétexte d'un échange de messages, les énoncés les plus divers revendiquent - et s'intègrent - valeurs et significations contextuelles propres à la situation épistolière. La variable ici réside dans la référence liant le texte à cette situation : de la représentation d'une pratique vécue, à la pure fiction rhétorique. Missives versifiées, qu'adressent à un protecteur, à un confrère, un ami (...). Êpitres amoureuses, où l'imaginaire fonctionne dans les limites du vraisemblable "courtois", parfois parodiquement inversée. Êpitres d'outretombe, que légitime l'autorité des Heroïdes ovidiennes (...) Êpitres enfin adressées à une collectivité sommairement définie, classe d'individus supposée réceptive de la communication... ${ }^{17}$

Também no CGGR, tudo é motivo para se dirigir a alguém através das "lettres missives". As cartas ora estão designadas como tal na didascália ou no corpo do poema, ora seu enunciado permite inferir pertencer a composição ao gênero epistolar. É assim que, nas esparsas, esse gênero se desenvolve, do mesmo modo que em todas as outras peças do gênero presentes no Cancioneiro resendiano.

Quanto às esparsas de circunstância, fato observado por Pierre Le Gentil e acima descrito, há de fato um grande número de poemas. Contudo, aquelas cuja temática é o amor, aliadas às de temática variada, mostram que esses poemas superam a simples circunstancialidade. Talvez Le Gentil tenha se prendido ao fato de que uma boa parte das composições cancioneiris, em Resende, tenha por característica a preocupação com assuntos mundanos. Uma vista d'olhos nessas peças, entretanto, mostra que a esparsa vai além da preocupação com

\footnotetext{
${ }^{16}$ ZUMTHOR, Paul. Le carrefour des rhétoriqueurs. Intertextualité et Rhétorique. Poétique, Paris, n. 27, p. $328,1976$.

${ }^{17}$ Ibidem, p. 328-329.
} 
trivialidades. A começar pela constatação de que algumas delas levam à criação de um exemplum. É o que se observa nas esparsas 6, 39 e 868, por exemplo.

Ainda quanto a essa espécie de esparsas, vale registrar que, sem a intervenção didascálica de Garcia de Resende, o fato quase não poderia ser entendido. Há casos em que, para explicar a situação, Resende escreve um texto cuja extensão equivale à da própria esparsa. Veja-se a seguinte didascália, explicando uma poema de dez versos: “De Joam Fogaça a ũu frade d'oservancia, que ia por guardiam a Tanjere e pedio-lhe que pedisse ao Conde Prior que escrevesse ao Capitam, seu filho, que o favorecesse laa. E deu-lhe esta trova pera o Conde."18. Tanto nesta esparsa quanto em algumas outras, Resende denomina os poemas "trovas" em vez de "esparsa"; conforme comentado anteriormente - um fio tênue separa ambas as formas quando compostas de apenas uma estrofe.

Ressaltem-se outras características desses poemas monostróficos compilados por Resende: a de no. 331 é um recado ao destinatário da esparsa; a no. 360 está endereçada e parece ter sido escrita pelo próprio poeta, pois vem abaixo da didascália de Garcia de Resende ("A ũa senhora que se chamava Costa"). A esparsa 539 distingue-se das demais por apresentar um mote em castelhano ("Gram miedo tengo de mi".) ${ }^{19}$ e será glosado na mesma língua - tem, então, característica de um vilancete. O poema 672 é um acróstico, em que o poeta canta seu amor por Dona Jlaria, valendo-se do " $\mathrm{j}$ " como som de " $\mathrm{i}$ ", certamente para se adequar a um jogo.

Feitas essas considerações, passa-se a um estudo mais específico de algumas esparsas, com o intuito de se entender sua forma e conteúdo. Todas podem ser consideradas exemplos de tradição e inovação, como se poderá constatar.

\section{Novos perigos, novos tempos, mas ainda um amor "mortal" e que provoca temor ao poeta}

Na esparsa no. 6, composta por Dom João de Meneses, Garcia de Resende explica, na didascália, que Luís da Silveira parte de Lisboa para Tânger a fim de participar do cerco a essa cidade. Leia-se a "Trova sua que mandou a Luis da Silveira, que partia de Lixboa ao cerco de Tanjer":

Co estes ventos d'agora a

perigoso é navegar, $\quad b$

que se mudam cada hora, a

${ }^{18}$ Cf. CGGR, op.cit., n. 319, II, p. 198-199.

${ }^{19}$ D. João de Meneses também glosou este mote em uma cantiga (Cf. CGGR, op.cit., I, p. 155). 


$\begin{array}{ll}5 \text { e quem vai de foz em fora } & \text { a } \\ \text { nunca mais poode tornar. } & \text { b } \\ \text { O navio pend'à banda, } & \text { c } \\ \text { a rezam nam é ouvida, } & \text { d } \\ \text { a vontade tudo manda, } & \text { c } \\ \text { e quem ha-d'andar desanda, } \mathrm{c} \\ 10 \text { quem tem alma nam tem vida. }\end{array}$

$\mathrm{d} \quad(C G G R, \mathrm{I}, 134-135)$

A esparsa é uma décima com ritmo irregular, próprio dos redondilhos maiores, e com rimas misturadas abaabcdccd; as rimas do grupo a são de natureza feminina (grave), e as do grupo b, masculina (aguda), na primeira quintilha; já na segunda quintilha, mantém-se apenas a rima feminina. Tal esquema rímico/rítmico coaduna com o tema da esparsa: os perigos de se navegar em direção à guerra. Contudo, o mais interessante é o fato de aflorar neste curto poema uma preocupação recente: as Conquistas ultramarinas. Nos quatro primeiros versos, o poeta relata os perigos do navegar - aquele que parte para uma empreitada marítima "nunca mais poode tornar"; na segunda parte da décima, Dom João reproduz o movimento do navio e como isso muda o estado de espírito do navegante. Sem dúvida, o fato circunstancial é nada mais do que o ponto de partida para o poeta criar uma máxima sobre as Conquistas: elas desestabilizam a vida de quem navega, o que está engenhosamente explicado pela annominatio antitética "andar desanda" e pela antítese "quem tem alma nam tem vida" 20 . É de se notar que, como preceito básico de uma máxima, o poeta tende a personificar seres inanimados; é o que acontece com os termos "rezam" (que não é ouvida) e "vontade" (que tudo manda $)^{21}$.

Quanto ao segundo grupo de esparsas, cuja temática é o amor, o CGGR, como todas as outras composições, apresenta-as espalhadas pelos quatro volumes. No entanto, as esparsas de amor estão mais concentradas no quarto e último volume: dos 28 poemas distribuídos, 17 deles têm Amor por tema. Tomem-se como exemplos duas esparsas, uma de Fernão da Silveira, poeta e coudel-mor, dos mais ativos e criativos poetas do Compêndio. O poema de Fernão da Silveira intitula-se "Memorial do Coudel-Moor.", cujo termo

\footnotetext{
${ }^{20}$ Juan Casas Rigall classificaria tal recurso como derivatio, devido ao emprego do prefixo que altera o sentido do verbo "andar". (CASAS RIGALL, Juan. Agudeza y retórica en la poesia amorosa de cancionero. Santiago de Compostela: Universidade, Servicio de Publicacións e Intercambio Científico, 1995, p. 228-229).

${ }^{21}$ Duarte da Gama fez umas trovas glosando esta esparsa: "Grosa de Duarte da Gama à trova de Dom Joam de Meneses, em contrairo de sua grosa.". Observe-se que Garcia de Resende dá nome de trova à esparsa. (Cf. op.cit., CGGR, III, 531).
} 


\section{Revista Signum, 2011, vol. 12, n. 1.}

"memorial" já requer, de certa forma, uma datação, registro que se comentará adiante. Leia-se o poema:

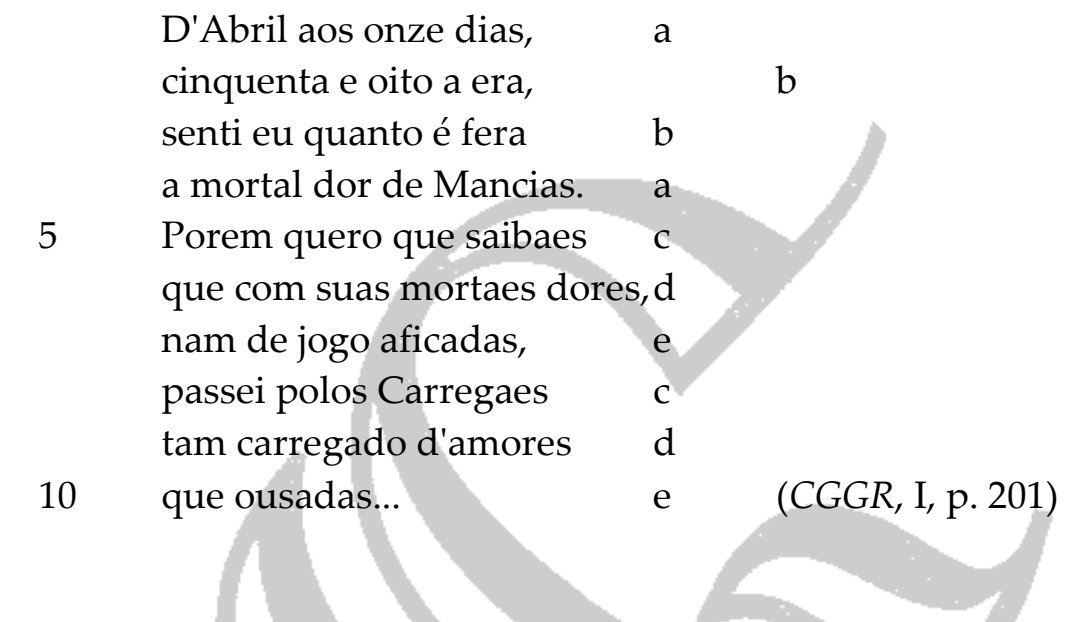

Silveira compara seu sofrimento de amor àquele de Macias, trovador galego do século XV muito cultuado pelos poetas palacianos de Espanha e Portugal, menos por sua produção poética que por seu drama amoroso; tornouse símbolo do amor sofrido e exemplo para os amantes ${ }^{22}$. O poema, que leva o no. 55, está em décima e apresenta um esquema rimático clássico nos quatro primeiros versos - abba; nos outros, o esquema é de rimas misturadas cdecde e parece ter a ver com a intensidade das dores que transportam o enamorado para os Carregaes, topônimo no plural usado não somente para adequar a rima, mas para criar uma paronomásia com o verbo "carregar", que segue no verso seguinte: tem sentido não de "trazer", "levar", mas de "pleno", "cheio" de

\footnotetext{
${ }^{22}$ Aida Fernanda Dias (2003, p. 809) explica que Macias era representado no Cancionero de Baena e que morreu pela lança do marido da mulher que amava. "Porque amou e serviu lealmente, tornou-se presença obrigatória nos chamados Infernos de amor e o exemplo para todos os fiéis amadores, que ousam algumas vezes afirmar a força do seu bem-querer superior àquela que viveu e matou o próprio Macías". (Cf. DIAS, op.cit., 2003, p. 809). Quanto a essa esparsa, Maria Isabel Morán Cabanas comenta que "o nome de Macías faz parte de uma construção perifrástica que, com valor hiperbólico, refere a doença de amor ou o chamado amor hereos". (Mitificação de Macias o Namorado no Cancioneiro Geral de Garcia de Resende. In: Mitos (Actas del VII Congreso Internacional de la Asociación Española de Semiótica). Universidad de Zaragoza, Zaragoza, 1996, vol. III, p. 198). Joaquín González Cuenca informa que "Macías, 'el Enamorado', trovador gallego al servicio de don Enrique de Villena (es su 'doncel'), se convirtió pronto en continuo objeto de referencia (...) como prototípico mártir de amor y víctima de un marido celoso. A medio camino entre la realidad y la leyenda, antes que el Romanticismo lo consagrara como trágico enamorado, ya lo había hecho la tardía Edad Media (...) no faltando su presencia en las enumeraciones de amantes célebres o infiernos de enamorados, como el de Garci Sánchez de Badajoz. Cantigas suyas como Cativo de miña tristura o Amor cruel e brioso, copiados en cancioneros como el de Baena, son objeto de citas y glosas". (Cf. CASTILLO, op.cit., p. 19-20, Tomo II).
} 
amores. É, no entanto, um amor que o faz perder-se. O Coudel-Mor ousa, ainda, deixar o último verso incompleto: usa um pé quebrado, e a incompletude é marcada pelas reticências ${ }^{23}$. Ainda quanto ao sistema rimático, Silveira adota a rima interna nos versos cinco e seis, "saibaes/mortaes", o que parece enfatizar sua vontade de mostrar a intensidade da dor de amar. Note-se que o poeta inicia sua esparsa registrando a data em que se sentiu ferido por essa dor. Fernão da Silveira, em muitas das suas composições, adotava esse procedimento, ou por motivos lúdicos ou por herança medieval. Segundo Ernst Robert Curtius,

as razões decisivas para a propagação dessa técnica de composição [estariam], em primeiro lugar, no conceito sagrado do número e, em segundo lugar, na falta de ulteriores preceitos para a dispositio. Com o uso da composição numérica, o poeta da Idade Média atingia um duplo fim: um esqueleto formal para a construção e uma profundidade simbólica ${ }^{24}$.

Jacques Le Goff também refere a questão de datação durante o medievo:

A Idade Média, tão ávida de datar como nós, não datava, porém, de acordo com as mesmas normas nem segundo as mesmas necessidades. O que, para datar, lhe importava era diferente do que a nós nos importa hoje (...). Simplesmente, quando não eram exactos era porque não sentiam necessidade de o ser, porque o quadro de referência do acontecimento considerado não era o dos números. Mas é raro que falte uma referência temporal ${ }^{25}$.

Vale lembrar que, para Hilário Franco Júnior, "'número' não era uma quantidade exata, e, sim, mais um instrumento de decodificação do possível

\footnotetext{
${ }^{23}$ Quanto a essa esparsa, escreve Jorge A. Osório: “O jogo entre o topónimo conhecido de toda a gente, 'Carregaes', e o sintagma 'carregado d'amores' pertence ao exercício retórico desta poesia, que trabalhava, no fundo, com um espectro relativamente pequeno de figuras e de vocabulário; por exemplo não avançava para o enriquecimento expressivo da metáfora". Em nota, escreve ainda: "Trata-se claramente de uma trova (sic) inacabada; mas o compilador nada diz sobre a condição do texto". (OSÓRIO, Jorge A. Do Cancioneiro "ordenado e emendado" por Garcia de Resende. Revista da Faculdade de Letras, Linguas e Literaturas, Porto, Universidade do Porto, II série, v. XXII, p. 324, 2005).

${ }^{24}$ CURTIUS, Ernst Robert. Literatura Europeia e Idade Média Latina. São Paulo: Ed. Hucitec, 1996, p. 622). As trovas nos. 78 e 81 (CGGR, I, p. p.251-254 e p. 259-260) também podem ser citadas como exemplos de enumeração.

${ }^{25}$ LE GOFF, Jacques. A civilização do ocidente medieval. Lisboa: Ed. Estampa, 1983. Vol. I, p. 218.
} 
mundo ${ }^{26 \prime}$. Percebe-se que não é o caso da datação usada, não só por Fernão da Silveira, mas por outros poetas do CGGR; provavelmente isso se deve ao aperfeiçoamento das técnicas de datação e, mais que tudo, à necessidade que o homem do fim do medievo, observando as mudanças de seu tempo e a importância que o registro histórico começava a ter, vê nesse procedimento um meio de registrar seu tempo.

A esparsa do Coudel-mor retrata, ainda nos fins do medievo, uma tradição que vem dos poetas trovadorescos - a "coita de amor" - tema que serviu a muitos dos poemas palacianos, como se poderá ver no exemplo tirado do último volume do CGGR, em sequência.

Essa outra esparsa (no. 790), de Antoneo Mendez, vem composta em décima, com rimas misturadas abaab no primeiro quinteto e cdcdc no último; as rimas do esquema a e c trazem palavras de forte intensidade e remetem ao sofrimento de amor: mal / mortal / tal / tormento / perdimento / consento - é um amor que traz sensação de morte e "perdimento", mas que, no entanto, o enamorado "consente", conforme o verbo que fecha o poema. Mendez começa o sétimo verso repetindo a palavra "tormento", que encerra o sexto verso, para enfatizar o mal que o amor da dama lhe provoca. Esse recurso lembra as coblas capdenals e o leixa-pren trovadorescos, muito usados nas cantigas de amor e de amigo, consoante a leitura que os poetas palacianos faziam dos poemas provençais e trovadorescos, adaptando-os e renovando-os. Leia-se o poema "Esparça sua.":

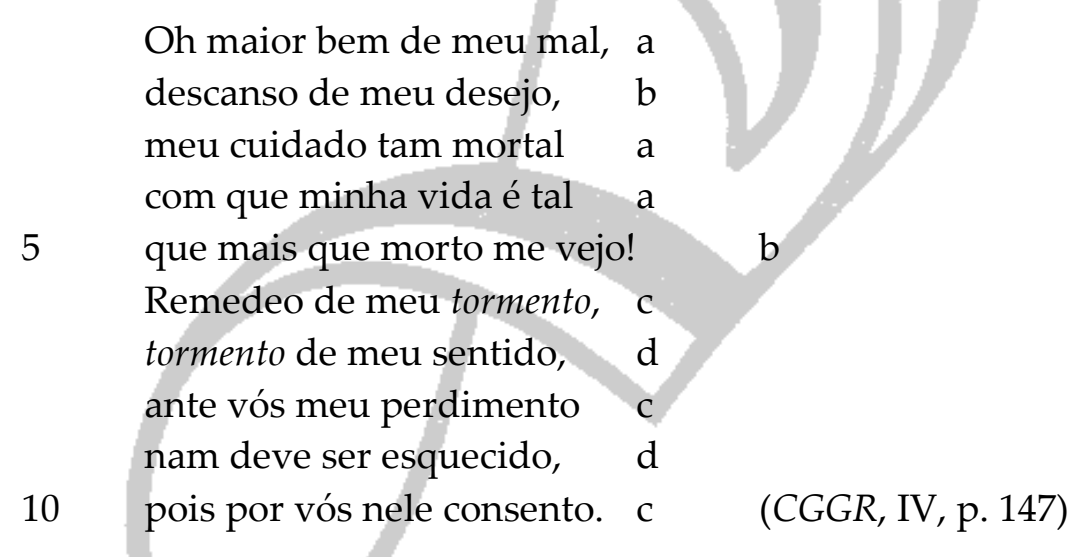

O poeta inicia sua esparsa com a expletiva "oh". Roland Barthes comenta que "a exclamação corresponde ao rapto brusco da palavra, à afasia emotiva; a dúvida, a dubitatio (nome de uma figura), à tortura das incertezas de conduta

${ }^{26}$ FRANCO JÚNIOR, Hilário. Modelo e imagem: o pensamento analógico medieval. In: IV Encontro Internacional de Estudos Medievais. 2001, Belo Horizonte, Anais. Belo Horizonte: PUC Minas, 2003, p. 41. 


\section{Revista Signum, 2011, vol. 12, n. 1.}

(Que fazer? isto? aquilo?), à leitura difícil dos 'signos' emitidos pelo outro...27". Quanto a essa figura, Le Gentil usa o termo "apóstrofe" e diz que os poetas do CGGR

renchérissent avec une habilité particulière, obtenant des effects analogues à ceux que recherchait Charles D'Orléans. Eux ne se bornent pas (...) à la pure et simple apostrophe (...) ils font néanmoins de leurs sentiments de vrais personnages (...) le ton est plus intime (...) vivent la même vie qu'eux-mêmes et souffrent comme eux. ${ }^{28}$

Já Antonio de Nebrija chama de "interjección" essa parte da oração gramatical, classificando-a como "advérbio", e vê nela certa "pasión del ánima" ${ }^{29}$. Esses comentários reforçam a intenção do poeta de expressar um amor sofrido, que o atormenta, mas que ele "consente".

O penúltimo grupo de esparsas traz por tema um novo sentimento explorado pelos poetas medievais: o "eu" dividido - ou "desavindo", para os poetas palacianos. A composição é a de no. 539 e foi composta por Duarte da Gama. A forma dessa esparsa é inusitada, pois traz um mote, glosado pelo poeta:

\section{ESPARÇA DE DUARTE DA GAMA \\ A ŨA SENHORA, QUE PÔS EM \\ ŨU LIVRO SEU Ũ MOTO \\ QUE DIZ:}

Gram miedo tengo de mi.

\footnotetext{
${ }^{27}$ BARTHES, Roland. A retórica antiga. In: A aventura semiológica. Trad. Maria de Sta. Cruz. Lisboa: Ed. 70, 1985, p. 88.

${ }^{28}$ Cf. LE GENTIL, op.cit., 1949, p. 182. Edmond Faral diz que "l'apostrophe y est d'un emploi courant et, à partir du XIe. siècle, en constitue une piece de style : apostrophes aux personnes défunts ou disparues, apostrophes à des abstractions personnifiées, la Mort, l'Amour, la Fortune, apostrophes à des objets inanimés, la terre, un pays, une ville, une chambre, une épée, etc.". (FARAL, Edmond. La disposition.. In: Les arts poétiques du XII.e et du XIII.e Recherches et documents sur la technique littéraire du Moyen Âge. 1. ed. Paris: Skalatine/Campion, 1982, p. 72).

${ }^{29}$ Assim se expressa Nebrija quanto às interjeições: “Los latinos (...) pusieron la interjección por parte de la oración distinta de las otras; pero nosotros, a imitación de los griegos, contámosla con los adverbios. Así que será interjección una de las significaciones del adverbio, la cual significa alguna pasión del ánima con voz indeterminada, como 'ai', del que se duele; 'hahaha', del que se rie; 'tat tat', del que vieda; y así de las otras partecillas por las cuales demostramos alguna pasión del ánima” (NEBRIJA, op.cit., Livro III, Cap. XVI).
} 


$\begin{array}{lll} & \text { Temo yo lo que temia } & \text { a } \\ & \text { y más lo que vos temeis, } & \text { b } \\ \text { temo más lo que solia } & \text { a } \\ \text { temer quando me partia } & \text { a } \\ 5 \text { donde vos os partireis. } & \text { b } \\ \text { Y con este tal sentido } & \mathrm{c} \\ \text { tantos temores me di, } & \text { d } \\ & \text { que sin ser de vos partido } & \mathrm{c} \\ & \text { com temor de vuestro olvidoc } \\ 10 \quad \text { gram miedo tengo de mi. } & \text { d }\end{array}$

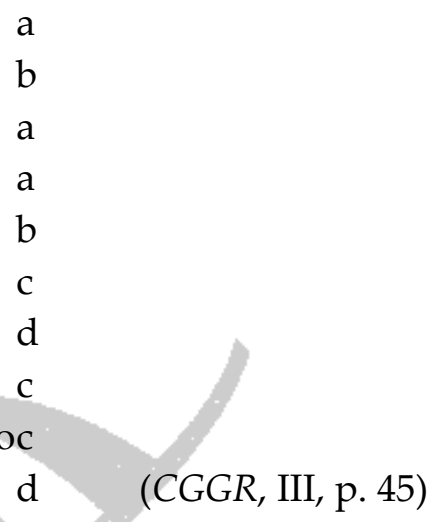

c

(CGGR, III, p. 45)

Essa composição é uma das cinco esparsas que vêm compostas em castelhano, e, para enfatizar a perdição de si mesmo, o poeta usa o verbo "temer", no primeiro verso, no presente do indicativo e no passado, mostrando com isso seu desencontro; o mesmo verbo é usado no segundo verso, agora na segunda pessoa, referindo-se àquela a que serve e que também teme o estado "desencontrado" do poeta. Nos versos três e quatro, recorre a esse verbo novamente, mas na primeira pessoa do singular, no tempo presente e no infinitivo. $\mathrm{O}$ verbo transformar-se-á em substantivo nos versos sete e nove - $\mathrm{o}$ primeiro no plural, indicando a intensidade do temor, palavra que reaparece no singular. Tanto a referência a "temer", nas conjugações vistas, e a "temores" e "temor" antecipam a força do substantivo "miedo", que, para o poeta, é a soma dos temores, pois de quem ele tem medo é de si mesmo, por achar-se perdido. O esquema rimático é também diversificado, já que apresenta rimas misturadas abaab, no primeiro quinteto, e cdccd, no último; as rimas são agudas, masculinas, exceto nos sexto, oitavo e nono versos, que são femininas e marcam o desencontro do poeta: sentido / partido / olvido. As rimas são formadas por verbos, logo pobres, exceto as dos versos sete e dez, que são ricas, agudas e podem ser entendidas como algo que o poeta deu a ele mesmo: "tantos temores me di / gram miedo tengo de $m i^{\prime \prime}$.

Finalmente, uma esparsa que traz por tema outra preocupação dos poetas palacianos, ao menos daqueles que se voltam para a indagação sobre os "novos tempos". O poema é de Francisco Homem, no. 759. Garcia de Resende parece novamente confundir a forma, trocando "esparsa" por "trova". Eis a "Trova sua a ũu homem, que se queixava do tempo.":

$\begin{array}{ll}\text { Como o tempo é de mudanças } & \mathrm{a} \\ \text { busca sempre meios tais } & \mathrm{b} \\ \text { que no que mais desejais } & \mathrm{b} \\ \text { daa mui longas esperanças. } & \mathrm{a}\end{array}$


$5 \quad$ Nam quer senam que gasteis somanas, meses e anos e ele com seus enganos traz encubertos os danos de males que nom sabeis. c

$\mathrm{d}$

$\mathrm{d}$

$\mathrm{d}$

c (CGGR, IV, p. 114)

A esparsa agora é composta em nona, com rimas misturadas abba no primeiro quarteto, mas alterna bruscamente para cdddc no sexteto, como que para enfatizar as mudanças alegadas no primeiro verso. Para o poeta, este tempo de mudanças traz esperanças, o que se divisa nos quatro primeiros versos; no entanto, tudo é engano, pretexto do tempo para dissimular, por semanas, meses e anos os males que não se conhecem. Dirigido a quem reclamava do tempo, na verdade o poeta reforça o protesto, já que o tempo encobre a esperança e só desvela os males. É uma clara demonstração do estado de espírito do homem que assiste às mudanças: esperançoso, mas enganado. Observe-se que o tempo é personificado e é sujeito do poema.

Pôde-se verificar, nesses poemas analisados, que os poetas não se prendiam apenas aos fatos circunstanciais; pelo contrário, temas mais espirituais e mesmo recorrentes, como o amor, formam a maioria das peças. Além disso, muitas esparsas serviram para a produção de exempla.

Neste rápido estudo tentou-se abordar, de forma sucinta, o modo composicional dos poetas palacianos que, tomando tanto temas próprios da medievalidade, como novos temas, cultivaram uma forma composicional fixa, advinda dos trovadores provençais e trovadorescos, a qual permitia o improviso, dada a sua extensão, mas propiciando inovações na própria forma. Pôde-se verificar, ainda, que as esparsas não se prendiam apenas aos fatos circunstanciais; pelo contrário, temas mais espirituais e mesmo recorrentes, como o amor, formam a maioria dessas peças. Além disso, serviram muitas esparsas como pretexto para a produção de um exemplum, muito ao gosto do homem medieval. Ao persistirem duas formas antigas - a esparsa e a cantiga ${ }^{30}-$, em número razoável, percebe-se não só o culto à tradição, mas um motivo para inovar. O poeta palaciano quatrocentista e quinhentista português encontra na pervivência de formas e conteúdos uma certa maneira de homenagear os antigos trovadores, adicionando novas formas e novos temas, antecipando

${ }^{30}$ Registram-se no Cancioneiro Geral 343 cantigas, o grupo mais numeroso dentro da compilação, $39,0 \%$ do total de poemas selecionados por Resende. Esse considerável número de cantigas indica que pervive um gosto essencialmente medieval, uma vez que ela é produto próprio dessa época. 


\section{Revista Signum, 2011, vol. 12, n. 1.}

produções renascentistas e barrocas. Nas palavras de Andrée Crabbé Rocha, esses poetas

trabalham a sua forma, procurando dar-lhe a maior perfeição possível. Isto pode dar-se em detrimento da beleza e da poesia, é certo, pois se trata dum esforço do intelecto mais do que da sensibilidade, mas contribui largamente para dotar os poetas imediatamente posteriores dum instrumento já posto à prova ${ }^{31}$.

As composições aqui apresentadas podem ser essa prova a que se refere a estudiosa.

${ }^{31}$ ROCHA, Andrée Crabbé. Aspectos do Cancioneiro Geral. Coimbra: Coimbra Ed., [s.d]. (Colecção Universitas), p. 94. 